ERRATUM Int. Agrophys., 2015, 29, 283-289

doi: 10.1515/intag-2015-0033

\title{
Erratum to: Atmospheric moisture controls far-red irradiation: a probable impact on the phytochrome**
}

\author{
Andrzej Doroszewski, Tadeusz Górski, and Jerzy Kozyra* \\ Department of Agrometeorology and Applied Informatics, Institute of Soil Science and Plant Cultivation \\ - National Research Institute, Czartoryskich 8, 24-100 Puławy, Poland
}

Received June 18, 2014; accepted May 31, 2015

Corrected Fig. 2 and caption of Fig. 4:

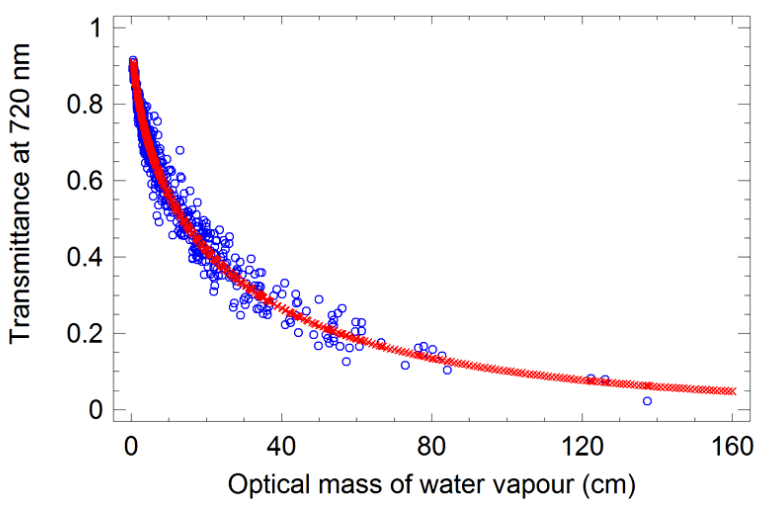

Fig. 2. The transmission of direct solar radiation at $720 \mathrm{~nm}$ as related to the optical mass of water vapour.
Fig. 4. The ratio of red to far-red $(660 / 720 \mathrm{~nm})$ global irradiance in dry atmospheres (water vapour content lesser than $15 \mathrm{~mm}-$ squares) and in moist atmospheres (higher values of water vapour - crosses) as related to the solar angle (h).
*Corresponding author e-mail: kozyr@iung.pulawy.pl

**This study was supported by the project Monitoring of Agricultural Drought in Poland by the Ministry of Agricultural and Rural Development, 2007-2015.
(C) 2015 Institute of Agrophysics, Polish Academy of Sciences 